Urologe 2018·57:529

https://doi.org/10.1007/s00120-018-0664-9

Online publiziert: 3. Mai 2018

(c) Springer Medizin Verlag $\mathrm{GmbH}$, ein Teil von Springer Nature 2018

CrossMark

V. Stratmann - P. Herrmann - M. Kretz

Springer Medizin Verlag GmbH, Heidelberg, Deutschland

\title{
Neuer federführender Herausgeber für Der Urologe
}

Springer-Medizin-Verlag freuen sich daher sehr, dass Herr Prof. Dr. Theodor Klotz dem Ruf gefolgt ist und die Nachfolge von Herrn Prof. Dr. Lümmen antritt (• Abb. 2).

Herr Prof. Dr. Theodor Klotz ist Chefarzt an der Klinik für Urologie, Andrologie und Kinderurologie am Klinikum Weiden der Kliniken Nordoberpfalz und gleichzeitig mit einem halben Kassenarztsitz im Urologiezentrum Schwandorf niedergelassen. In diesem Zusammenhang wird er zukünftig die Besonderheiten als niedergelassener Urologe in die Waagschale werfen und besonderen Wert auf die Gegebenheiten des Alltags niedergelassener Urologen und Urologinnen legen. Dabei werden gesundheits- und berufspolitische Aspekte der ambulanten Versorgung sowohl wissenschaftlich als auch praktisch beleuchtet. Neben den, im Peer-review-Prozess begutachteten, wissenschaftlichen Artikeln und der hochkarätigen Fortbildung, für die Der Urologe steht, ist auch die Berufspolitik eine

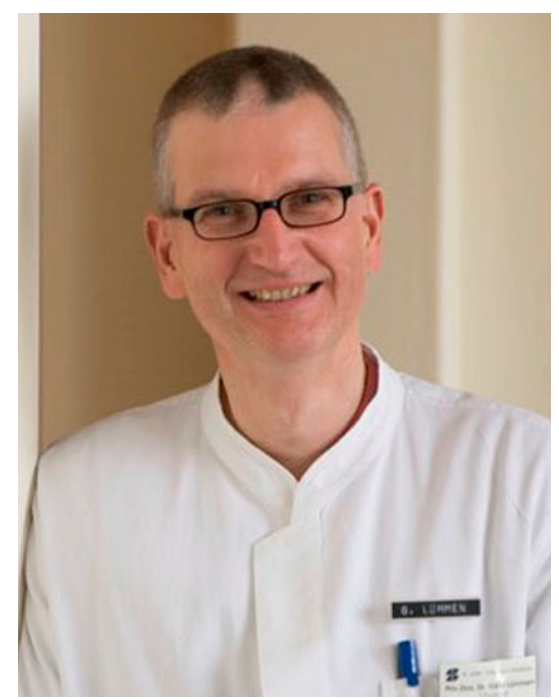

Abb. 1 ^ Prof. Dr. Gerd Lümmen starke und wichtige Säule. Diesen Gedanken des Abwechslungsreichtums möchte Herr Prof. Dr. Klotz zusammen mit Herrn Prof. Dr. Wullich und dem gesamten Herausgeberboard zukünftig noch stärker in den Fokus rücken.

Wir freuen uns auf die Zukunft von Der Urologe und wünschen Herrn Prof. Klotz einen guten Start.

\section{Korrespondenzadresse}

\section{Stratmann}

Springer Medizin Verlag GmbH

Tiergartenstr. 17, 69121 Heidelberg,

Deutschland

verena.stratmann@springer.com

Interessenkonflikt. V. Stratmann, P. Herrmann und M. Kretz geben an, dass kein Interessenkonflikt besteht.

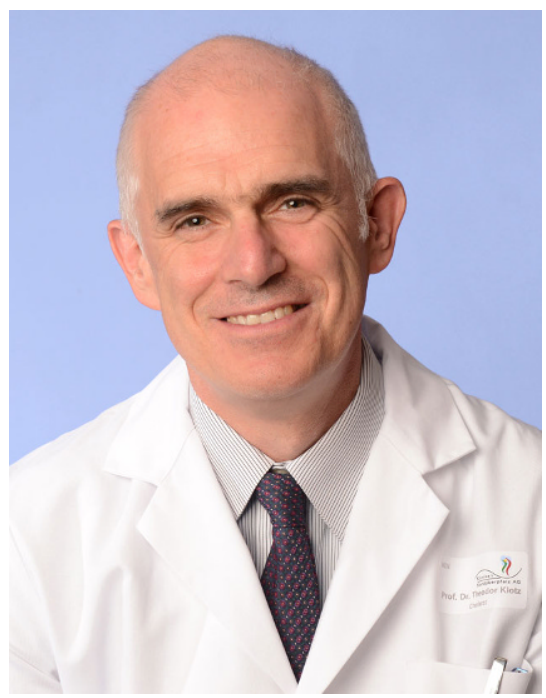

Abb. 2 ム Prof. Dr. Theodor Klotz 